\title{
90K, an interferon-stimulated gene product, reduces the infectivity of HIV-1
}

\author{
Veronika Lodermeyer ${ }^{1}$, Kristina Suhr ${ }^{1,4}$, Nicola Schrott ${ }^{1}$, Christian Kolbe ${ }^{1}$, Christina M Stürzel ${ }^{1}$, Daniela Krnavek ${ }^{1}$, \\ Jan Münch ${ }^{1}$, Christian Dietz ${ }^{2}$, Tanja Waldmann ${ }^{3}$, Frank Kirchhoff ${ }^{1}$ and Christine Goffinet ${ }^{1,4^{*}}$
}

\begin{abstract}
Background: In response to viral infections, interferons induce the transcription of several hundred genes in mammalian cells. Specific antiviral functions, however, have only been attributed to a few of them. 90K/LGALS3BP has been reported to be an interferon-stimulated gene that is upregulated in individuals with cancer or HIV-1 infection.

Results: Here, we show that 90K expression dose-dependently decreased the particle infectivity of HIV-1 progeny. The lower infectivity of released particles correlated with reduced virion incorporation of mature envelope glycoproteins gp120 and gp41. Further, proteolytic processing of the gp160 precursor and surface expression of gp120 in the producer cell were impaired in the presence of 90K expression. In contrast, expression of Gag, Nef and Vpu, and virus release were not grossly affected by $90 \mathrm{~K}$ expression. 90K-imposed restriction occurred in the absence of direct interaction of 90K with HIV-1 Env or entrapment of Env in the ER. The cell-associated, but not the secreted species of 90K, mediated the antiviral effect. A truncated version of human 90K, solely consisting of the two intermediate domains, displayed a similar antiviral activity as the full-length wildtype 90K, indicating that the N-terminal SRCR-like domain and the C-terminal domain are dispensable for 90K's antiviral activity. The murine homolog of 90K, CypCAP (Cyclophilin C-associated protein), neither modulated particle infectivity of HIV-1 nor lowered the virion incorporation of mature gp120, suggesting a species-specific mode of action. 90K was expressed at basal levels in TZM-bl cells and in primary macrophages, and at low levels in CD4 ${ }^{+}$T-cells and PBMCs. 90K's susceptibility to IFN-mediated stimulation of expression was cell type-specific. siRNA-mediated knockdown of 90K in TZM-bl cells and primary macrophages enhanced the incorporation of Env glycoproteins into progeny virions, boosted the particle infectivity of released HIV-1, and accelerated HIV-1 spread. Conversely, treatment of HIV-1 infected macrophages with IFN-a induced 90K expression and lowered the particle infectivity of HIV-1.
\end{abstract}

Conclusions: Thus, 90K constitutes a novel antiviral factor that reduces the particle infectivity of HIV-1, involving interference with the maturation and incorporation of HIV-1 Env molecules into virions.

Keywords: Interferon, HIV-1, Antiviral factor, Env incorporation

\section{Background}

Human cells are equipped with antiviral proteins that are capable of disturbing various steps of the replication cycle of diverse viruses. Notable examples of anti-HIV-1 factors include members of the apolipoprotein editing complex (APOBEC) class of cytidine deaminases, which induce lethal hyper-mutations of the viral genome [1], Tetherin/CD317/ BST2, which causes retention of viral particles on the

\footnotetext{
* Correspondence: christine.goffinet@twincore.de

'Institute of Molecular Virology, UIm University Medical Center, UIm, Germany

${ }^{4}$ TWIINCORE, Institute of Experimental Virology, Feodor-Lynen-Strasse 7,

30625 Hannover, Germany

Full list of author information is available at the end of the article
}

infected cell's surface [2,3], and SAMHD1, that prevents reverse transcription in myeloid cells and resting $\mathrm{CD} 4^{+} \mathrm{T}$-cells [4-6]. Expression of these restriction factors is typically interferon (IFN)-responsive [7], and HIV-1 infection results in their enhanced transcription both ex vivo [8] and in vivo [9].

90K/LGALS3BP, which encodes for a secretory glycoprotein of 585 amino acids, shares these properties. By virtue of an IFN-responsive element in the $90 \mathrm{~K}$ promoter [10], levels of mRNA are enhanced by type I and type II IFNs in PBMCs [11-13]. Induction of 90K protein expression by IFN- $\alpha$ has been shown in carcinoma cell lines $[14,15]$ as well as in vivo following IFN- $\alpha$ administration to cancer patients $[14,16]$. Furthermore, HIV-1

\section{Biomed Central}


infection has been reported to potentiate expression of $90 \mathrm{~K}$ in primary $\mathrm{CD}^{+} \mathrm{T}$-cell cultures [8] as well as in vivo in HIV-1 infected individuals [9,17-22], although it remains unclear whether the enhanced $90 \mathrm{~K}$ levels can be attributed to HIV-1-infected cells or uninfected bystander cells in vivo.

$90 \mathrm{~K}$, originally identified as a tumor-associated antigen $[14,23,24]$, is a member of the family of scavenger receptor cysteine-rich (SRCR) domain-containing proteins [25]. It enters the secretory pathway by virtue of its $\mathrm{N}$-terminal signal peptide and is $N$-glycosylated in the endoplasmic reticulum and Golgi complex [26]. Secreted 90K protein is present in the $\mu \mathrm{g} / \mathrm{ml}$ range in several body fluids of healthy individuals, including blood, semen, urine, tears, saliva, and breast milk $[18,27,28]$. Its physiological functions seem to comprise roles in immune response modulation and cell adhesion. Specifically, secreted 90K promoted NK cell activity, $\mathrm{CD}^{+}$T-cell-mediated lysis activity and cytokine production [11]. Furthermore, secreted $90 \mathrm{~K}$ induced homotypic cell adhesion and the formation of multicellular aggregates of tumor cells [29] by binding to galectin-3/Mac-2.

The inducibility of $90 \mathrm{~K}$ expression by IFNs and its upregulated expression in HIV-1 infected individuals prompted us to investigate whether $90 \mathrm{~K}$ modulates HIV-1 replication. In this study, we establish $90 \mathrm{~K}$ as an antiviral factor that is associated with the release of poorly infectious virions. This involved defective maturation of HIV-1 Env during de novo virus production and reduced incorporation of Env into progeny virions. The two central protein-binding domains of $90 \mathrm{~K}$ were essential and sufficient for its antiviral infectivity. $90 \mathrm{~K}$ protein expression was cell typespecific, and the degree of IFN-mediated upregulation of $90 \mathrm{~K}$ at the protein level differed between macrophages and $\mathrm{CD}^{+}{ }^{+} \mathrm{T}$-cells. Depletion of endogenous $90 \mathrm{~K}$ in HIV-1 susceptible cells, including TZM-bl cells and primary macrophages, boosted the particle infectivity of progeny HIV-1, ameliorated Env incorporation into nascent virions and accelerated the spread of HIV-1. Reduction of 90K expression in PBMCs likewise enhanced HIV-1 spread. Concordantly, IFN- $\alpha$ treatment of primary HIV-1 infected macrophages lowered the particle infectivity of viral progeny. These data suggest that $90 \mathrm{~K}$ is an important contributor of the cellular antiviral defense against HIV-1 infection.

\section{Results}

90K expression reduces the particle infectivity of HIV-1 progeny by interfering with the maturation and incorporation of the viral Env glycoproteins into progeny virions

In order to investigate whether $90 \mathrm{~K}$ may affect HIV-1 replication, 293T cells were cotransfected with a proviral HIV-1 DNA and decreasing amounts of an expression plasmid for C-terminally myc-tagged 90K (90K-myc). Notably, transfection of $293 \mathrm{~T}$ cells with a 90K-encoding plasmid resulted in levels of $90 \mathrm{~K}$ expression that were clearly higher than those obtained following IFN stimulation (Additional file 1: Figure S1A). Anti-p24 capsid ELISA analysis showed that 90K-myc expression did not modulate the levels of released HIV-1 capsid in the supernatant (Figure 1A). In contrast, 90K-myc decreased the quantity of infectious HIV-1 released in the culture supernatant (Figure 1B). Consequently, the particle infectivity (infectivity per ng p24CA) was dose-dependently reduced by $90 \mathrm{~K}-$ myc expression (Figure 1C).

Anti-HIV-1 p24 capsid Western Blotting of sucrose cushion-purified supernatants of the producer cells confirmed that 90K-myc did not affect levels of released viral p24 capsid antigen but, in contrast, induced a dosedependent decrease in virus-associated gp120 and gp41 Env proteins (Figure 1D).

ELISA analysis of corresponding cell lysates did not show any detectable effect of $90 \mathrm{~K}$ expression on cell-associated levels of HIV-1 capsid (Figure 1E). Calculation of HIV-1 capsid release showed that $90 \mathrm{~K}$ did not interfere with HIV-1 release (Figure 1G). However, a profound impact of $90 \mathrm{~K}$ expression on the relative proportion of the uncleaved gp160 precursor and its cleavage products was disclosed (Figure 1F). Specifically, expression of 90K-myc reduced the relative amounts of mature gp120 and gp41, respectively, whereas it increased the relative levels of uncleaved gp160 precursor (Figure 1F). Of note, the effect on gp41 processing was generally lower than on gp120, possibly due to increased sensitivity of the anti-gp41 antibody to cleaved gp41. Thus, $90 \mathrm{~K}$ expression affected the proteolytic maturation and virion incorporation of the HIV-1 Env glycoproteins. Importantly, 90K specifically inhibited Env biosynthesis, since neither the expression levels of other viral proteins, including HIV-1 Nef, Gag and $\mathrm{Vpu}$, nor Gag processing were grossly affected by 90K-myc expression (Figure 1F). Further, expression of the $g f p$ reporter gene was not affected by $90 \mathrm{~K}-\mathrm{myc}$, demonstrating that global cellular protein biosynthesis was not disturbed. 90K-myc expression also reduced the particle infectivity of R5-tropic HIV-1 $1_{\mathrm{LAI}}$ and HIV-1 $1_{\mathrm{YU}-2}$, as well of three transmitted/founder HIV strains (Additional file 2: Figure S2), indicating that its antiviral activity is not restricted to viruses of a specific tropism or to laboratoryadapted viral strains.

90K-myc-mediated inhibition of Env biosynthesis and of Env virion incorporation occurred in the absence of any detectable signs of cytoxicity, as assessed by 7-AAD stain and a luminometric metabolism assay of 90K-mycexpressing cells (Additional file 3: Figure S3). We next tested whether expression of 90K-myc in a HIV-1susceptible $\mathrm{T}$-cell line might equally result in a reduction of HIV-1 infectivity. For this purpose, we cotransfected 
the T-cell line SupT1 with HIV-1 proviral DNA and an expression vector for $90 \mathrm{~K}$-myc or the respective empty vector control. Sucrose cushion-purified virions from 90Kmyc-expressing producer cells displayed reduced particle HIV-1 infectivity, compared to empty vector-expressing cells (Figure $1 \mathrm{H}$ ). Thus, $90 \mathrm{~K}$ is also able to reduce the specific infectivity of progeny HIV-1 in T-cells.
Infrared imaging-based protein quantification of Western Blots from multiple experiments corroborated that 90K-myc expression dose-dependently suppressed both the particle infectivity of released HIV-1, and the incorporation of mature gp120 into virions. A statistical analysis established a significant correlation of both parameters in a 90K-dose dependent manner (Figure 2A). Importantly, 


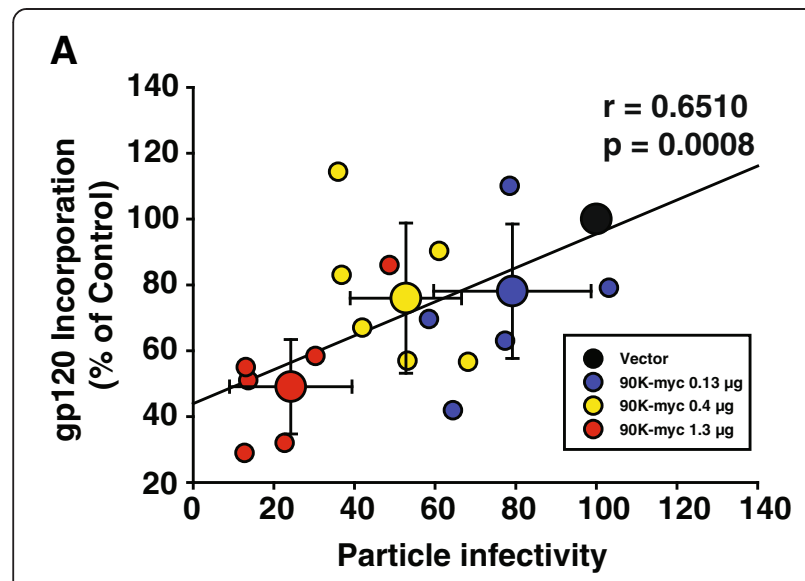

B

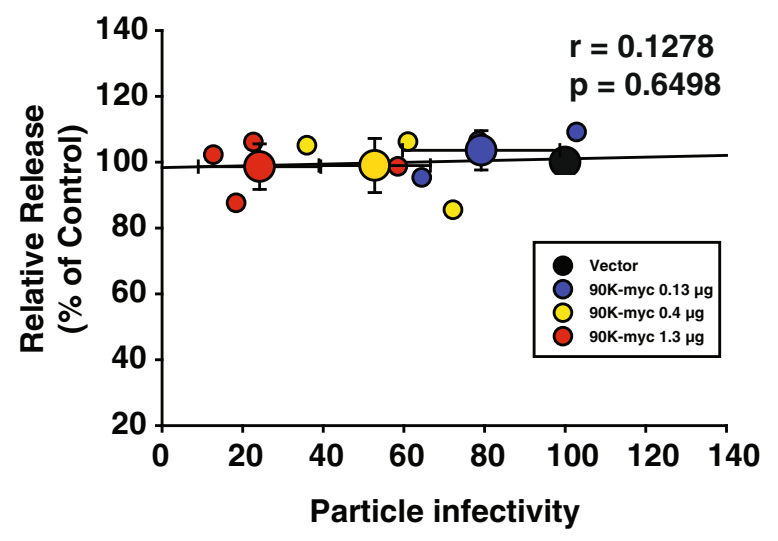

C

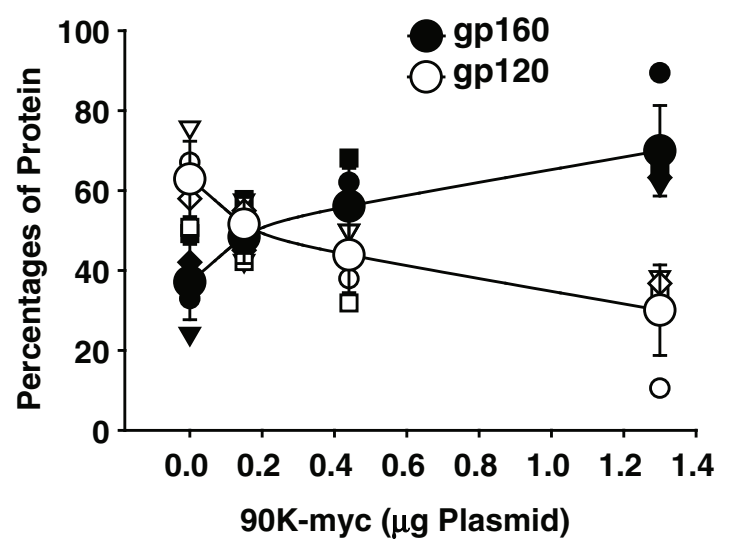

Figure 2 90K-induced reduction of HIV-1 particle infectivity correlates with defective gp120 incorporation into progeny, without influencing virus release. (A) Correlative analysis of gp120Env content per p24CA and HIV-1 particle infectivity (infectivity per ng p24) in the supernatant as a function of 90K plasmid amount. Small symbols represent the values of each individual transfection; large symbols represent the arithmetic means \pm S.E.M. of five-six individual experiments. The Pearson's correlation coefficient $r$ and the corresponding p value were calculated using GraphPad Prism Software. (B) Correlative analysis of relative released virus and HIV-1 particle infectivity (infectivity per ng p24) in the supernatant as a function of 90K plasmid amount. Small symbols represent the values of each individual transfection; large symbols represent the arithmetic means \pm S.E.M. of four individual experiments. The Pearson's correlation coefficient $r$ and the corresponding $p$ value were calculated using GraphPad Prism Software. (C) Relative percentage of cell-associated gp120Env or gp160 Env versus total detected anti-gp120 signal as a function of cotransfected 90K plasmid amount. Values were obtained by Infrared imaging-based quantification of signals. Small symbols represent the values of each individual experiment; large symbols represent the arithmetic means \pm S.E.M. of four individual experiments.

HIV-1 release was not affected (Figure 2B). Quantification of the signal intensities for cell-associated gp120 and gp160 confirmed that 90K dose-dependently reduced the proportion of processed, mature gp120 relative to the uncleaved gp160 precursor from 63\% to 30\% (Figure 2C).

Defective maturation of de novo HIV-1 Env may interfere with its subcellular transport towards the plasma membrane, explaining the paucity of mature HIV-1 Env in released virions. To investigate whether cell surface levels of HIV-1 Env are altered in the presence of 90K, $293 \mathrm{~T}$ cells were cotransfected with a proviral DNA encoding a GFP reporter gene, and 90K-myc or vector and then subjected to HIV-1 Env surface staining. Surface Env expression was reduced three-fold by $90 \mathrm{~K}$ (Figure 3A-B)). Importantly, 90K did neither interfere with the subcellular trafficking of another glycoprotein, human $\mathrm{CD} 4$, to the cell surface (Additional file 4: Figure S4A-C), nor did it reduce its half-life (Additional file 4: Figure S4D). In contrast, HIV-1 Vpu efficiently prevented accumulation of $\mathrm{CD} 4$ at the cell surface and reduced CD4 steady state levels (Additional file 4: Figure S4C-D).

Our results showed that the antiviral activity of $90 \mathrm{~K}$ involved interference with the proteolytic maturation of HIV-1 Env (Figure 1). During its biosynthesis, the proteolytic cleavage of the HIV-1 Env precursor is mediated by cellular furins and furin-like enzymes residing in the transGolgi compartment of the infected cell [30]. We thus next analyzed whether $90 \mathrm{~K}$ may broadly interfere with the proteolytic cleavage of furin-dependent viral and cellular glycoproteins. Similarly to provirally expressed HIV-1 Env, proteolytic processing of CMV promoter driven HIV-1 Env was two-fold less efficient in the presence of $90 \mathrm{~K}$ (Figure 3C), demonstrating that this effect does not 


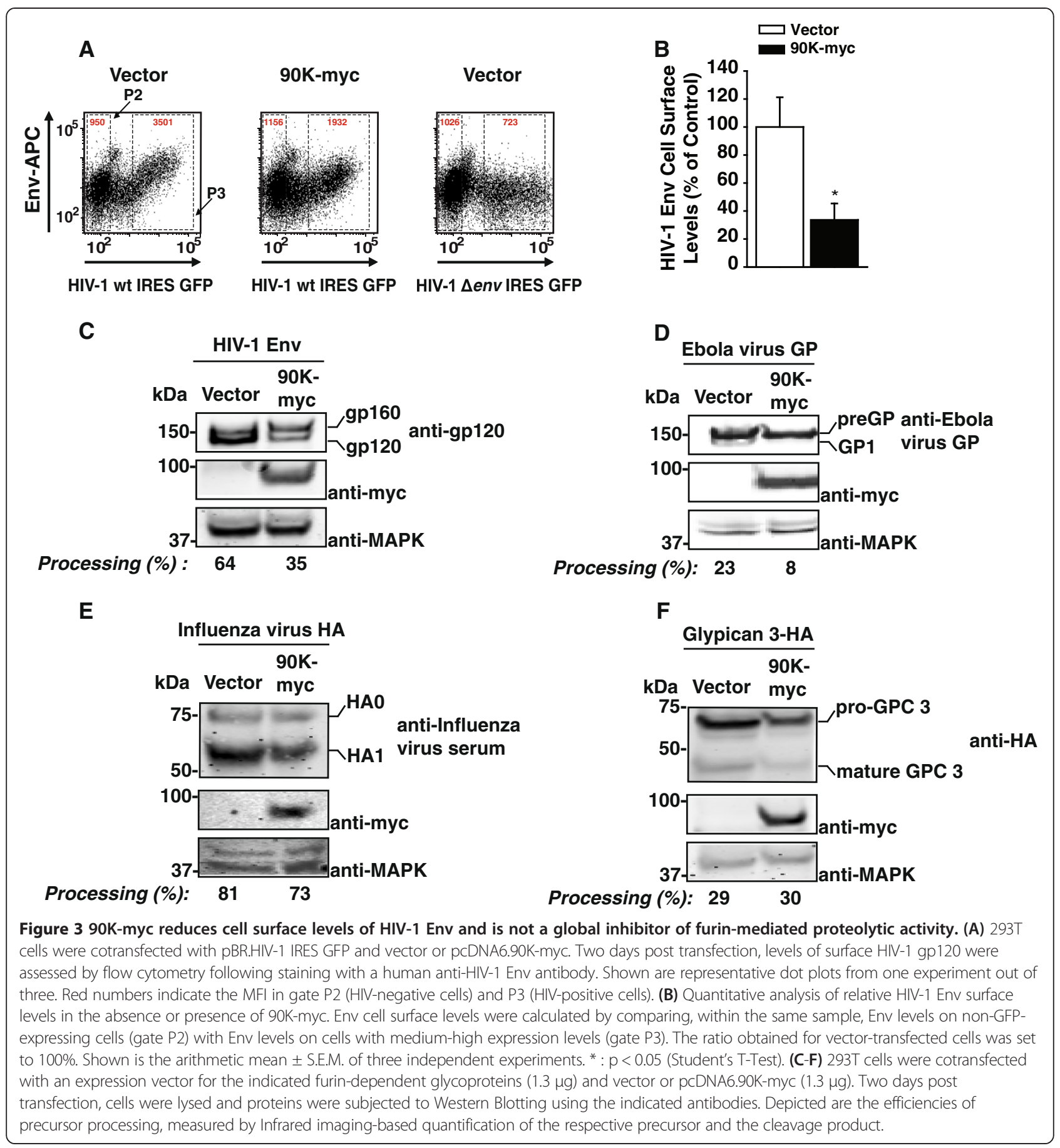

require expression of other HIV-1 proteins. Interestingly, cleavage of the precursor of Ebola GP, preGP, was also impaired (3-fold) by 90K (Figure 3D), whereas proteolytic processing of Influenza virus glycoprotein precursor HA0 and of the precursor of cellular glypican-3, two prototypic furin substrates, was less or not significantly influenced (Figure 3E-F).

Although sensitivities of the furin substrates to physiologic furin concentrations may differ, these results do not provide evidence for a global interference of $90 \mathrm{~K}$ with furin-mediated cleavage of protein precursors and suggest a specific effect on selected viral glycoproteins. Alternatively, 90K may interfere with HIV-1 Env's biosynthesis by trapping it in the ER, thus hampering the accessibility of the HIV-1 Env precursor to the furin-positive cis-Golgi compartment. We thus probed a direct interaction of HIV-1 Env and 90K. Multiple efforts to immunoprecipitate HIV-1 Env by anti-90K antibodies or vice versa did not 
provide evidence for a direct interaction of both proteins, despite colocolization of HIV-1 Env and 90K-myc (Additional file 5: Figure S6A-B). In contrast, direct interaction of HIV-1 Env and CD4 could be shown (Additional file 6: Figure S5), Deglycosylation tests further failed to disclose any 90K-dependent changes in the subcellular trafficking of HIV-1 Env. Specifically, PNGase treatment efficiently deglycosylated gp160, gp41 and 90K (Additional file 7: Figure S7A). Treatment with endoglycosidase $\mathrm{H}$ (EndoH), which cleaves $\mathrm{N}$-linked high-mannose oligosaccharides specifically attached to proteins located in ER/cis-Golgi compartment, including HIV-1 gp160 [31,32], deglycosylated gp160 with the same efficiency in the absence and presence of $90 \mathrm{~K}$, arguing against $90 \mathrm{~K}$ retaining a significantly higher percentage of gp160 in the ER (Additional file 7: Figure S7B). In contrast, as expected [32], mature gp41 was resistant to EndoH deglycosylation. These results suggest that 90K-imposed antiviral activity does neither involve interference with furin activity, nor require a direct interaction with HIV-1 Env, nor influence the subcellular transport of the HIV-1 Env precursor from the ER to the cis-Golgi.

Conclusively, these results demonstrate that $90 \mathrm{~K}$ decreases the particle infectivity of newly synthesized HIV1 particles, probably by interfering with the maturation and incorporation of the viral glycoproteins via a yet to be elucidated mechanism.

The cell-associated, but not the secreted species of $90 \mathrm{~K}$, exerts the antiviral activity

By means of its N-terminal signal peptide, the glycoprotein $90 \mathrm{~K}$ is routed to the extracellular environment via the secretory pathway $[26,28]$. In order to decipher whether reinternalization of the soluble, secreted species, or the cell-associated form of $90 \mathrm{~K}$ is responsible for the antiviral effect, we inoculated pHIV- $1_{\mathrm{NL} 4.3}$-transfected 293T cells with supernatant of 90K-myc-transfected cells or vector-transfected cells (Figure 4A, left half). Regardless of presence or absence of 90K-myc in the supernatant, cells produced comparable levels of infectious HIV-1 (Figure 4A, left half), whereas cotransfection of 90K-myc potently inhibited HIV-1 infectivity. Consistent with this observation, preincubation of HIV-1 IRES GFP virions with $90 \mathrm{~K}$-containing supernatants did not affect their infectivity (Figure 4B).

Additionally, we made use of an ER-resident, secretionimpaired 90K-myc mutant, 90K(S223P)-myc [26]. Notably, 90K(S223P)-myc expression inhibited HIV-1 production to a similar extent as wildtype 90K-myc (Figure 4C). We confirmed that this mutant displays a reduced ability to be secreted (Figure 4C). Together, these findings favor a predominant, if not exclusive role of cell-associated 90K in reducing the levels of HIV-1 infectivity, whereas secreted $90 \mathrm{~K}$ seems to be dispensable for this restricting activity.

\section{Endogenous $90 \mathrm{~K}$ reduces the infectivity of HIV-1}

To examine whether endogenous $90 \mathrm{~K}$ displays anti-HIV-1 activity, we conducted a siRNA-mediated downmodulation of $90 \mathrm{~K}$ expression in the HIV-susceptible TZM-bl cell line. This cell line expressed relatively high endogenous levels of $90 \mathrm{~K}$, although still a factor of 11.5 -fold lower than the level obtained after transfection of 293T cells with the lowest effective $90 \mathrm{~K}$-myc plasmid dose $(0.15 \mu \mathrm{g})$ (Additional file 1: Figure S1B). Transfection of TZM-bl cells with a 90K-specific siRNA potently diminished $90 \mathrm{~K}$ protein expression as measured by immunofluorescence (Figure 5A), Western Blotting (Figure 5B) as well as 90K mRNA levels (Figure 5C), compared to cells transfected with an irrelevant control siRNA. Following siRNA-mediated downmodulation of $90 \mathrm{~K}$ expression, TZM-bl cells were infected with VSV-G-pseudotyped HIV-1 $1_{\text {NL4.3 }}$. Three days post infection, culture supernatants were analyzed for p24 capsid antigen release and particle infectivity. Importantly, 90K depletion barely affected HIV-1 p24 capsid release (Figure 5D), but boosted the particle infectivity of HIV-1 released into the supernatant by 11 -fold compared to control knockdown (Figure 5E), and 90K knockdown was shown to be efficient at the RNA and protein level (Figure 5F-G). Western Blot analysis of producer cell lysates revealed that $90 \mathrm{~K}$ depletion enhanced the efficiency of gp160 processing, resulting in higher levels of mature gp120 (Figure 5G), whereas HIV-1 p24 capsid expression was unaltered. Sucrose cushion-purified virions displayed increased amounts of incorporated mature gp120 (Figure 5H). Thus, the antiviral potential and mode of action observed for heterologous 90K (Figures 1 and 2) is recapitulated by endogenously expressed $90 \mathrm{~K}$, despite low expression levels of endogenous 90K.

\section{The two central protein-binding domains of $90 \mathrm{~K}$ are required and sufficient for its anti-HIV-1 activity}

$90 \mathrm{~K}$ is composed of a $\mathrm{N}$-terminal scavenger receptor cysteine-rich (SRCR) domain, a BTB/POZ domain, an IVR domain, and a C-terminal part without known homologies to other protein domains [11]. In order to identify domains which are critical for 90K's antiviral activity, we generated a set of truncated $90 \mathrm{~K}$ variants which each comprised two domains in their natural order (Figure 6A). All variants were $\mathrm{C}$-terminally myc-tagged, and encoded the authentic signal peptide. Following transient transfection, these variants were expressed at levels similar to those of wildtype 90K-myc, and they displayed the expected respective molecular weight (Figure 6B, [33]). Of note, single domains of $90 \mathrm{~K}$ were expressed at low to undetectable levels, precluding their use for mutational analysis of 90K's antiviral activity (data not shown). In order 


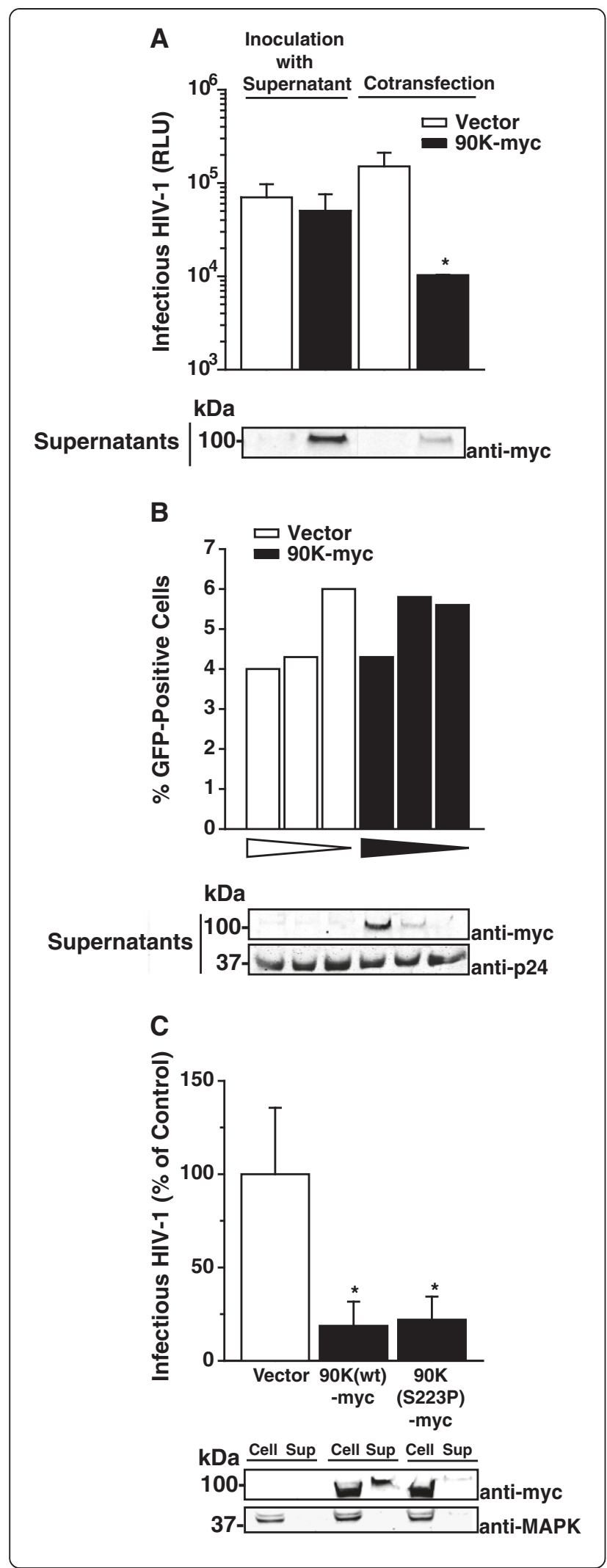

Figure 4 The cell-associated, but not the secreted species of 90K, exerts the antiviral activity. (A) 293T cells were either transfected with pBR.HIV-1 NL4.3 IRES GFP and inoculated with culture supernatant originating from vector-transfected or 90Kmyc-transfected 293T cells (left half), or cotransfected with HIV-1 wt and pcDNA6.90K-myc or empty vector (right half). Two days post transfection, the amount of infectious HIV-1 in the culture supernatant was determined. Shown are the arithmetic means \pm S.D. of triplicates originating from one representative experiment out of two. Supernatants of the cultures from (A) were analyzed for $90 \mathrm{~K}$-myc content. (B) A constant amount of HIV-1 IRES GFP virions was incubated for $15 \mathrm{~min}$ at $37^{\circ} \mathrm{C}$ with decreasing amounts of supernatant derived from 293T cells that had been transfected with empty vector or pcDNA6.90K-myc. TZM-bl were inoculated with the pretreated virus and analyzed for GFP expression three days later. Shown are the values of one representative experiment out of two. An aliquot of the pretreated inoculum that was given to the TZM-bl cells was analyzed by Western Blotting. (C) 293T cells were cotransfected with pBR.HIV-1 NL4.3 IRES GFP and indicated expression plasmids. Two days post transfection, the amount of infectious HIV-1 in the culture supernatant was determined. Values are normalized to the empty vector-cotransfected control. Shown are the arithmetic means \pm S.E.M. of three independent experiments. Cell lysates and supernatants from one representive experiment were analyzed by Western Blotting. ${ }^{*}: p<0.05$ (Student's T-Test).

to assess the ability of individual $90 \mathrm{~K}$ variants to interfere with the infectivity of HIV-1, 293T cells were cotransfected with proviral HIV-1 DNA and the indicated 90Kmyc variants or empty vector. Wildtype $90 \mathrm{~K}$-myc reduced the particle infectivity of HIV-1 virions released in the culture supernatant, whereas the particle infectivity of HIV-1 remained largely unchanged in the presence of $90 \mathrm{~K}(1,2)$-myc and $90 \mathrm{~K}(3,4)$-myc (Figure 6C). However, $90 \mathrm{~K}(2,3)$-myc was at least as potent in diminishing HIV-1 infectivity levels as wildtype $90 \mathrm{~K}$-myc, suggesting that the presence of the $\mathrm{BTB} / \mathrm{POZ}$ and IVR domains of $90 \mathrm{~K}$ is required and sufficient for 90K's antiviral activity. Importantly, $90 \mathrm{~K}(2,3)$-myc reduced the incorporation of HIV-1 gp120 even more potently than 90K-myc wildtype, whereas viruses produced in $90 \mathrm{~K}(1,2)$-myc and $90 \mathrm{~K}(3,4)$-myc expressing cells displayed normal levels of incorporated HIV-1 gp120 (Figure 6D). Furthermore, the proteolytic cleavage of gp160 in cells transfected with $90 \mathrm{~K}(2,3)$-myc was inefficient, like in $90 \mathrm{~K}$-myc wildtype cells, whereas $90 \mathrm{~K}$ $(1,2)$-myc and $90 \mathrm{~K}(3,4)$-myc induced only minor changes in the efficiency of Env processing (Figure 6E).

Conclusively, a region within the two intermediate protein-binding domains of $90 \mathrm{~K}$, the $\mathrm{BTB} / \mathrm{POZ}$ and the IVR domain, is required and sufficient for its ability to interfere with HIV-1 Env maturation and incorporation, whereas the scavenger receptor cysteine-rich domain and the C-terminal domain of $90 \mathrm{~K}$ are dispensable. 


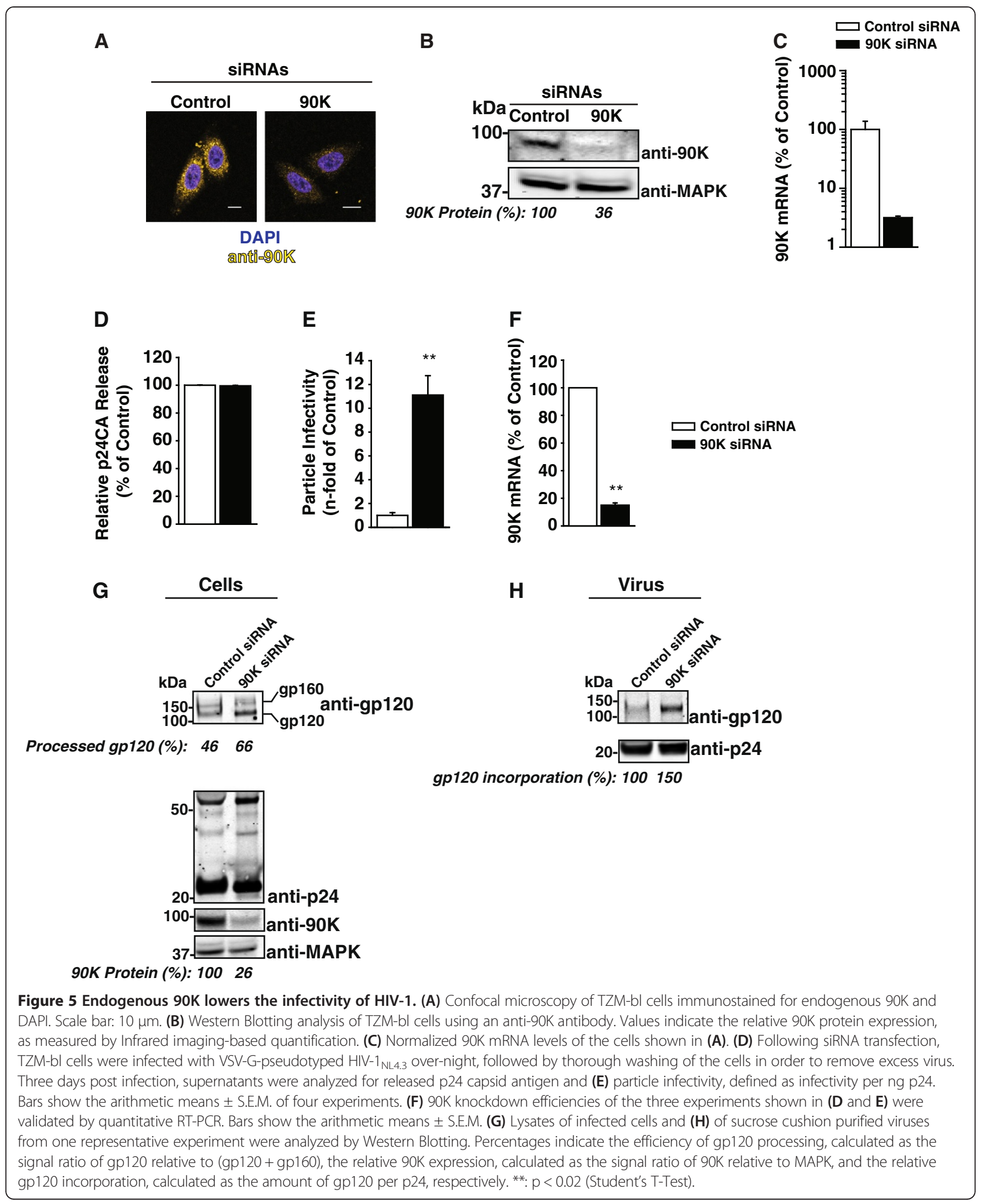

Species specificity of $90 \mathrm{~K}$-imposed antiviral activity Mice encode a 90K homolog, Cyclophilin C-associated protein (СypCAP), which displays 69\% homology on the amino acid level [34]. Human 90K and murine CypCAP share the protein organization and the ability to get secreted [35]. Of note, rodent cells display 


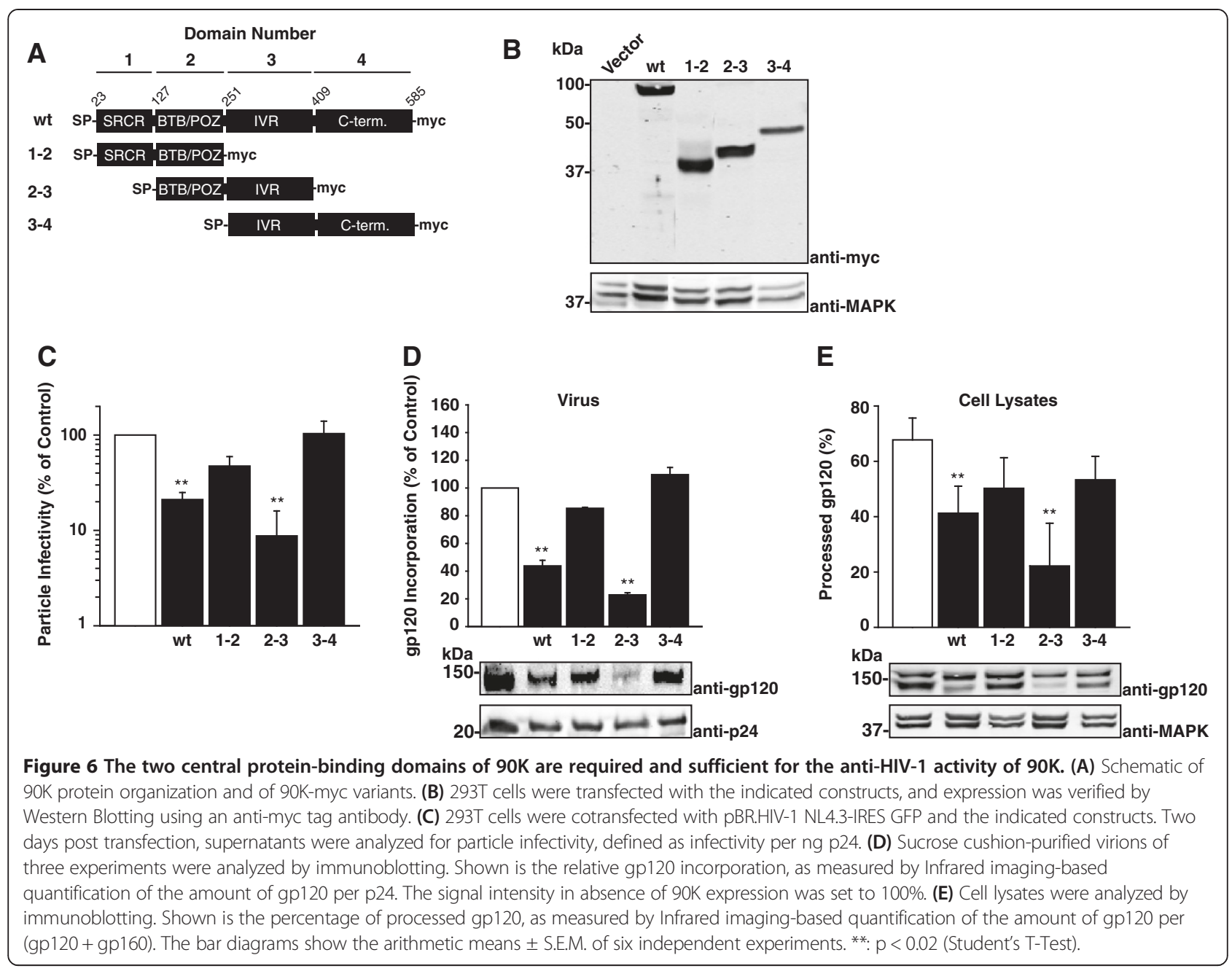

severe limitations in supporting the late phase of HIV1 replication, including virion assembly and infectivity [36], hampering the development of an immunocompetent small animal model of HIV infection.

We thus tested the ability of mouse CypCAP to reduce the particle infectivity of progeny HIV-1. Remarkably, the mouse homolog of $90 \mathrm{~K}$ failed to act antivirally, whereas human $90 \mathrm{~K}$ reduced the particle infectivity of HIV-1 (Additional file 8: Figure S8A). The lack of functional inhibition by mouse CypCAP was accompanied by normal Env glycoprotein incorporation (Additional file 8: Figure S8B). Although we observed a trend towards slightly decreased processing of the gp160 precursor, the difference was not statistically significant (Additional file 8: Figure $\mathrm{S} 8 \mathrm{C})$. Thus, these data suggest that the negative modulations of human $90 \mathrm{~K}$ on Env maturation and virion incorporation are required for its ability to reduce HIV-1 particle infectivity. Furthermore, CypCAP does not seem to contribute to the inefficiency of late steps of the HIV-1 replication cycle in murine cells.
Expression and susceptibility of $90 \mathrm{~K}$ to IFN stimulation in primary HIV-1 target cells

90K protein has been reported to be expressed in many tissues and tumor cell lines [11], but whether it is expressed in $\mathrm{CD} 4^{+} \mathrm{T}$-cells and macrophages that represent the primary HIV-1 target cells in vivo is poorly investigated. Thus, we examined endogenous $90 \mathrm{~K}$ mRNA and protein expression in these cell types. 90K mRNA was expressed in primary HIV-1 target cells, including activated PBMCs, $\mathrm{CD} 4^{+}$T-cells and monocyte-derived macrophages (Figure 7A). Notably, IL-2/mitogen stimulation increased $90 \mathrm{~K}$ messenger levels in PBMCs and $\mathrm{CD}_{4}{ }^{+}$ T-cells. In line with the documented IFN-responsiveness of 90K mRNA expression [14,15], treatment of primary PBMCs, stimulated $\mathrm{CD} 4^{+} \mathrm{T}$-cells, and monocyte-derived macrophages with IFNs resulted in a marked enrichment of 90K transcripts (Figure 7B).

We next assessed the relative levels of $90 \mathrm{~K}$ protein expression in HIV-1 target cells. Western Blot analysis failed to reproducibly reveal basal expression levels of 


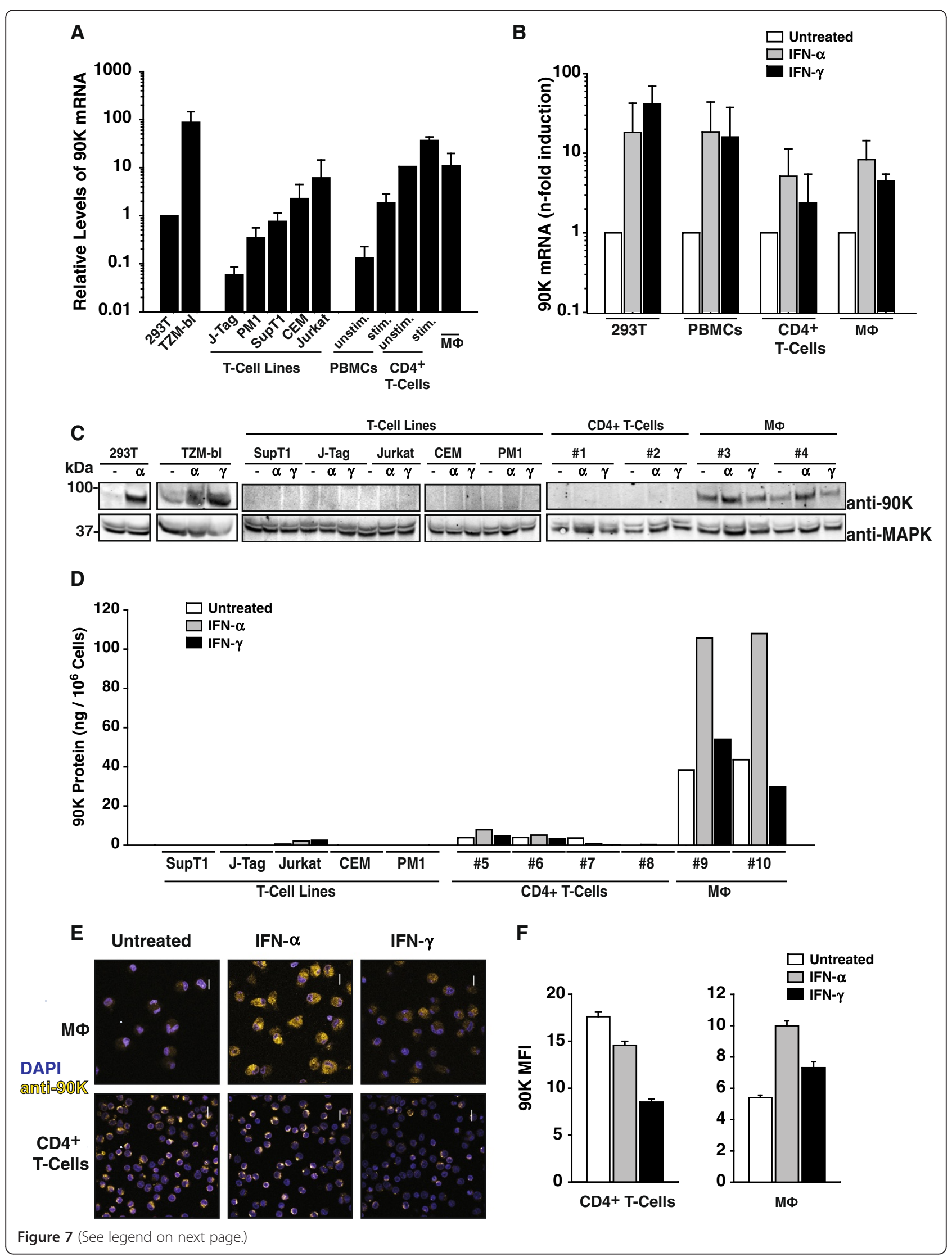


(See figure on previous page.)

Figure 7 Expression and susceptibility to IFN stimulation of $90 \mathrm{~K}$ in primary HIV-1 target cells. (A) CDNA was prepared from total RNA of the indicated cell lines and primary cells, and analyzed for relative 90K mRNA expression by TaqMan-based quantitative PCR with RNaseP expression as a reference. Depicted is the relative level of $90 \mathrm{~K}$ expression, and values obtained for $293 \mathrm{~T}$ cells were arbitrarily set to 1 . Histograms represent arithmetic means \pm S.E.M. of three independent experiments, except for the data for $C D 4^{+}$T-cells, which shows arithmetic means of two experiments.

(B) Indicated primary cell cultures were treated with IFN-a (100 U/ml) or IFN- $\gamma(100 \mathrm{U} / \mathrm{ml})$ for 24-48 hours, or left untreated, prior to RNA isolation and cDNA synthesis. Shown is the fold increase of 90K mRNA level from 2-3 experiments, each performed in duplicates. (C) Western Blot analysis of indicated cells treated with IFN-a $(100 \mathrm{U} / \mathrm{ml})$ or IFN- $-(100 \mathrm{U} / \mathrm{ml})$ for 48 hours, or left untreated. (D) Anti-90K ELISA of cell lysates, following treatment with IFN-a $(100 \mathrm{U} / \mathrm{ml})$ or IFN- $\gamma(100 \mathrm{U} / \mathrm{ml})$ for 48 hours where indicated. (E) Immunofluorescence stain of indicated primary cell cultures. Cells treated with IFN-a $(100 \mathrm{U} / \mathrm{ml})$ or IFN- $-(100 \mathrm{U} / \mathrm{ml})$ for $24-48$ hours where indicated or left untreated. Scale bar: $10 \mu \mathrm{m}$. (F) Quantification of $90 \mathrm{~K}$

immunofluorescence by KNIME image processing plug-in and the mean fluorescence intensity (MFI) signal per cell was determined. The data represent the arithmetic mean \pm S.E.M. of 154 untreated, 259 IFN-a-treated and 147 IFN-y-treated T-cells and the mean of 85 untreated, 121 IFN-a-treated and 64 IFN- - -treated macrophages.

90K in multiple T-cell lines, activated PBMCs (data not shown) and $\mathrm{CD} 4^{+}$T-cells (Figure $7 \mathrm{C}$ ), despite detection of $90 \mathrm{~K}$ mRNA (Figure 7A), whereas all tested macrophages scored positive (Figure $7 \mathrm{C}$ ). IFN- $\alpha$, and, to a lesser extent, IFN- $\gamma$ treatment enhanced $90 \mathrm{~K}$ protein levels in macrophages (Figure 7C). Both IFN- $\alpha$ and IFN $-\gamma$ treatment failed to induce $90 \mathrm{~K}$ protein expression in $\mathrm{CD}^{+}{ }^{+}$-cells to levels detectable by Western Blotting.

In order to verify the findings on $90 \mathrm{~K}$ expression obtained by Western Blotting, we made use of a sensitive commercial anti-90K antigen ELISA for analysis of cellassociated $90 \mathrm{~K}$ using lysates of T-cell lines and primary HIV-1 target cells. This assay revealed that 90K levels were close to the detection limit in Jurkat T-cells and $\mathrm{CD}^{+}{ }^{+} \mathrm{T}$-cells, whereas the other $\mathrm{T}$-cell lines scored negative. In macrophages, screening of macrophages from multiple donors by anti-90K ELISA confirmed that this cell type expresses higher $90 \mathrm{~K}$ protein levels than T-cells.

Immunofluorescence analysis revealed, intuitively intriguingly, higher $90 \mathrm{~K}$ staining intensities in $\mathrm{CD}^{+}$T-cells than macrophages (Figure 7E, middle and bottom panels, and Figure 7F). However, a direct comparison of the $90 \mathrm{~K}$ signals obtained in $\mathrm{CD} 4^{+} \mathrm{T}$-cells and macrophages by immunofluorescence seems inadequate, since macrophages and T-cells may greatly differ in their sensitivity to Triton permeabilization and thus to effective intracellular antibody concentrations. The intra-cell type comparison of IFN-mediated upregulation, however, confirmed that IFN$\alpha$ increased 90K expression in macrophages, but not in $\mathrm{CD} 4{ }^{+} \mathrm{T}$-cells. Together, $90 \mathrm{~K}$ is expressed in macrophages and, at low levels, in $\mathrm{CD}_{4}^{+} \mathrm{T}$-cells.

\section{Reduction of endogenous $90 \mathrm{~K}$ expression enhances the particle infectivity of HIV-1, increases HIV-1 Env content of progeny virions and accelerates viral spread in primary HIV-1 target cells}

Basal $90 \mathrm{~K}$ levels in primary macrophages were up to 9-fold lower than levels obtained by transfection of 293T cells with the lowest effective 90K-myc plasmid dose $(0.15 \mu \mathrm{g})$ (Additional file 1: Figure S1C). In order to assess the antiviral potential of these low endogenous $90 \mathrm{~K}$ expression levels in this primary HIV-1 target cell type, we infected primary macrophages with VSV-G/HIV- $1_{\mathrm{NL} 4.3}$ and subsequently reduced $90 \mathrm{~K}$ expression by RNAi. Virions purified from culture supernatants of infected macrophages were examined for their particle infectivity and for their protein composition. Particle infectivity was enhanced by $90 \mathrm{~K}$ depletion (Figure 8A), and levels of HIV-1 Env were increased in virions produced by $90 \mathrm{~K}$-depleted macrophages compared to virus which originated from control siRNA-transfected cultures, corroborating 90K's ability to induce a paucity of mature Env in virions (Figure 8A). Analysis of corresponding cell lysates showed that the efficiency of HIV-1 Env processing was only mildly increased, suggesting that 90K's primary mode of action in macrophages is the inhibition of virion incorporation of HIV-1 Env, rather than inhibition of Env biosynthesis. We next tested whether $90 \mathrm{~K}$ depletion influences HIV-1 spread in primary macrophages. For this purpose, macrophages from two donors were transfected with a 90K-specific or a control siRNA and subsequently infected with macrophage-tropic HIV-1 $1_{\mathrm{Ba}-\mathrm{L}}$. Supernatants were analyzed for p24 capsid amounts released in the culture supernatant as a result of HIV-1 spread. Notably, silencing of $90 \mathrm{~K}$ expression was stable and resulted in an enhanced spread of HIV-1 $1_{\text {Ba-L }}$ (Figure $8 \mathrm{~B}$ ), showing that low endogenous levels of $90 \mathrm{~K}$ protein can impose a hurdle to HIV-1 replication.

Given the $90 \mathrm{~K}$ upregulation following IFN- $\alpha$ stimulation in primary macrophages (Figure 7B-F), we next tested whether IFN- $\alpha$ treatment translates into a lower particle infectivity of HIV-1 produced in this primary cell type. For this purpose, we infected macrophages with HIV-1 $1_{\mathrm{Ba}-\mathrm{L}}$ in the presence or absence of a continuous and moderate dose of IFN- $\alpha(100 \mathrm{U} / \mathrm{ml})$. IFN- $\alpha$ treatment potently reduced the levels of released HIV-1 infectivity (Figure $8 \mathrm{C}$ ) and, to a lower extent, of released p24 antigen (Figure 8D), probably involving tetherinmediated inhibition of virus release [2,3]. At days 3,7 and 10 post initiation of IFN- $\alpha$ treatment and HIV-1 infection, the particle infectivity of HIV-1 was severely 
decreased by IFN- $\alpha$ treatment compared to no treatment (Figure 8E). Western Blotting of cell lysates demonstrated potent induction of $90 \mathrm{~K}$ expression at these time points, but not at day 1 post initiation of IFN- $\alpha$ treatment and HIV-1 infection, probably due to too short duration of IFN stimulation (Figure $8 \mathrm{~F}$ ). Due to IFN- $\alpha$-mediated upregulation of multiple genes, these results do not specifically address $90 \mathrm{~K}$ 's contribution to the IFN- $\alpha$-mounted antiviral response. However, they indicate the presence of IFN- $\alpha$-induced blocks to particle infectivity and suggest that $90 \mathrm{~K}$ may constitute a part of this antiviral defense response.

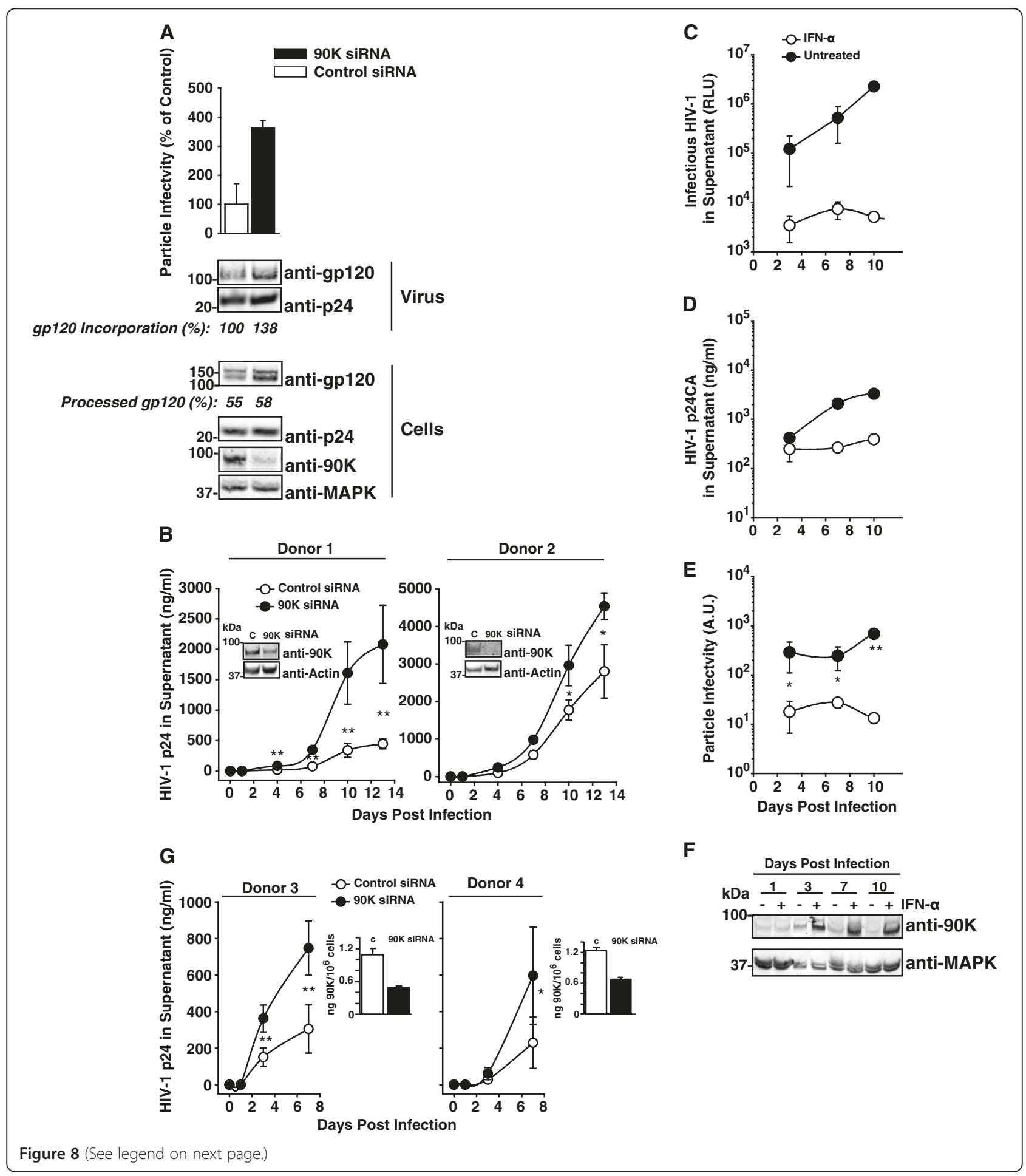


(See figure on previous page.)

Figure 8 Depletion of $90 \mathrm{~K}$ in primary HIV-1 target cells enhances particle infectivity, enhances Env content of HIV-1 particles, and accelerates HIV-1 spread. (A) VSV-G/HIV-1 NL4.3-infected macrophages were transfected one day post-infection with a 90K-specific or an irrelevant siRNA. At day 7 post infection, particle infectivity of released HIV-1 was calculated as the ratio of infectivity to p24 capsid antigen. Cell lysates and sucrose cushion-purified virus were analyzed by Western Blotting. Percentages indicate the relative gp120 incorporation and the efficiency of gp120 processing, calculated as in Figure 5 (G-H) (B) Macrophages obtained from two donors were siRNA-transfected and subsequently infected with HIV-1 Ba-L. $_{\text {. One day }}$ post infection, excess virus was removed by thorough washing. Supernatants were subjected to anti-p24 capsid antigen ELISA at indicated time points. Aliquots of cells were taken for 90K knockdown validation over time by Western Blotting. Shown is 90K expression at day 13 post infection.

(C) Macrophages were infected with HIV-1 Ba-L $_{\text {L }}$ and simultaneously treated with IFN-a $(100 \mathrm{U} / \mathrm{ml})$. Supernatants were harvested at the indicated time points, frozen, and analyzed for released p24 capsid and (D) infectious HIV-1. Shown are arithmetic means of triplicates \pm S.D. (E) Using the data from (C) and (D), the particle infectivity was calculated. Data points indicate arithmetic means of triplicates \pm S.D. (F) Cell lysates were subjected to Western Blotting using indicated antibodies. (G) IL-2/PHA-stimulated PBMCs from two donors were nucleofected with a 90K-specific or an irrelevant siRNA followed by HIV-1 NL4.3 infection over night. Excess virus was removed by thorough washing at indicated time points supernatants were subjected to p24 capsid antigen ELISA. 90K knockdown at the time point of infection was validated by 90K ELISA. * : $p<0.05 ;{ }^{* *}: p<0.02$ (Student's T-Test).

Finally, we tested whether low levels of 90K expression in primary PBMCs are sufficient for influencing HIV-1 replication. A two-fold reduction of $90 \mathrm{~K}$ expression resulted in a modest, but clearly detectable acceleration of HIV-1 spread in PBMC cultures infected with T-cell tropic HIV- $1_{\mathrm{NL} 4.3}$.

Together, these findings establish that, although low, endogenous levels of $90 \mathrm{~K}$ in primary HIV-1 target cells induce a paucity of mature Env molecules in newly synthesized HIV-1 particles, reduce the infectivity of HIV-1 and impair HIV-1 spread. These findings highlight the relevance of this antiviral factor in physiologic target cell types of HIV-1 infection.

\section{Discussion}

Although the transcription of many IFN-stimulated genes is induced upon contact of pathogens with the host cell, the direct contribution of most of their respective gene products to the mounting of an antiviral state is poorly investigated. Here, we propose that $90 \mathrm{~K}$ is a player of the intrinsic immune response that may contribute to HIV-1 restriction.

Two hallmarks of antiviral restriction factors are their ability to directly and dominantly inhibit specific steps of the virus replication cycle, and their IFN-induced or IFNstimulated expression. These criteria are fulfilled by $90 \mathrm{~K}$. First, heterologous expression and siRNA-mediated depletion studies demonstrated that $90 \mathrm{~K}$ reduces the particle infectivity of HIV-1, without interfering with particle release, expression of other viral proteins, or inducing detectable toxicity. Both heterologous $90 \mathrm{~K}$ as well as endogenous 90K, expressed in the HIV-1-susceptible TZM-bl cell line and, most importantly, in primary macrophages and primary PBMCs, were antiviral. Reduction of particle infectivity by $90 \mathrm{~K}$ coincided with inefficient proteolytic cleavage of the gp160Env precursor, reduced cell surface expression of HIV-1 Env, and limited incorporation of gp120 and gp41 into progeny virions.

Second, we and others [14-16] clearly demonstrate that $90 \mathrm{~K}$ expression can be induced or stimulated by IFN- $\alpha$.
Interestingly, 90K protein, but not mRNA, induction seems to be governed by cell type specific regulation. $293 \mathrm{~T}$ cells and macrophages, but not T-cells, were susceptible to IFN$\alpha$-mediated induction and stimulation of $90 \mathrm{~K}$ protein expression, respectively. In contrast, T-cells, in addition to displaying low to undetectable levels of $90 \mathrm{~K}$ expression, were refractory to IFN-mediated upregulation of $90 \mathrm{~K}$ protein expression. A recent study suggested that T-cells and macrophages, although equally responsive to IFN- $\alpha$ in terms of ISG mRNA upregulation, differ in their ability to mount an antiviral state upon IFN- $\alpha$-treatment, suggesting that ISG mRNA induction may not reflect the degree of protein upregulation in T-cells [37]. Future studies are required to study in depth the regulation of $90 \mathrm{~K}$ protein expression in T-cells.

Physiological levels of 90K in HIV-1-susceptible TZMbl cells, primary macrophages and PBMCs were clearly lower than ectopic antiviral 90K expression levels. Despite this fact, the limited level of endogenous $90 \mathrm{~K}$ expression clearly was able to diminish the particle infectivity of HIV-1, since siRNA-mediated depletion of endogenous $90 \mathrm{~K}$ in TZM-bl cells and primary macrophages resulted in an ameliorated particle infectivity of released virions and enhanced Env incorporation. In contrast, ectopic 90K protein seems to display, in relative terms, weak antiviral activity. Importantly, 90K knockdown resulted in accelerated spread of HIV-1 in primary macrophages and PBMCs. Interestingly, an IFN-induced loss of particle infectivity of newly synthesized HIV-1 particles has been described in PHA/IL-2-stimulated PBMCs [38] and myeloid U937 cells [39]. In these studies, the reduction of infectivity was attributed to an aberrant distribution of Env in intracellular compartments and a marked depletion of envelope glycoproteins in released virions. It is plausible that these effects are, at least partially, caused by $90 \mathrm{~K}$.

Since HIV-1 Env and 90K share, by means of their $\mathrm{N}$-terminal signal peptide, subcellular trafficking through the secretory pathway, it was tempting to speculate that a direct or indirect association of these two proteins is required for 90K's restricting activity. HIV-1 gp160Env 
molecules require proteolytic cleavage by cellular furin and furin-like enzymes located in the trans-Golgi network in order to reach fusogenicity. It is unlikely that ectopic $90 \mathrm{~K}$ expression globally interferes with the furin-mediated cleavage of glycoprotein precursors or with the subcellular trafficking of glycoproteins to the cell surface, since neither the processing efficiency of two other furin substrates, the precursors of FPV HA0 and of cellular glypican-3, nor the subcellular transport of cellular glycoprotein CD4 to the plasma membrane were grossly influenced by $90 \mathrm{~K}$. Of note, the HA0 precursor protein studied here is derived from the H7 HA of Influenza virus and displays a polybasic cleavage site (KKRKKR) which is highly efficiently cleaved by furin and may be less sensitive to modest changes of furin efficacy. HIV-1 Env, in contrast, has been reported to be a notoriously poor furin substrate [40] and might require much higher furin levels than the prototypic furin substrates HA and Glypican-3. Future goals will consist to probe direct or indirect interaction of furin and $90 \mathrm{~K}$. Notably, however, the proteolytic processing of the precursor of Ebola GP was severely impaired in the presence of $90 \mathrm{~K}$, suggesting that $90 \mathrm{~K}$ may reduce the particle infectivity of Ebola virus.

We next hypothesized that $90 \mathrm{~K}$ may prevent access of the unprocessed gp160 precursor to the furin-positive trans-Golgi compartment by a direct interaction, resulting in an abolished proteolytic cleavage and, as a consequence, in a reduced incorporation of mature gp120 into budding particles. This scenario, however, could not be substantiated by deglycosylation experiments and immunoprecipitation assays. These data, however, do not exclude an indirect association of $90 \mathrm{~K}$ and HIV-1 Env within a multiprotein complex. Mutational analysis revealed that the two central protein-binding domains, $\mathrm{BTB} / \mathrm{POZ}$ and IVR, are crucial for 90K's antiviral activity, whereas the SRCR domain and the carboxyterminal domain of $90 \mathrm{~K}$ were dispensable. Future work will consist to determine the exact mechanism of $90 \mathrm{~K}$-imposed inhibition.

Interestingly, the mouse homolog of $90 \mathrm{~K}$, CypCAP, failed to act antivirally. Cyclophilins catalyze petidyl-prolyl cis-trans isomerase reactions and assist protein folding [41]. Whether antiviral human 90K likewise modulates chaperone activity and whether this is required for exerting the antiviral effect is unknown. Importantly, the inactivity of the mouse protein was accompanied by absent alterations of gp120 incorporation and processing, suggesting that these two effects are crucial for human 90K's ability to reduce the particle infectivity of HIV-1. However, 90K's effect on gp120 processing was at best mild in primary macrophages, whether virion incorporation of Env was clearly increased, suggesting that inhibition of Env processing and virion incorporation are not necessarily coupled.
In healthy individuals, $90 \mathrm{~K}$ is present in multiple body compartments, including blood, semen, urine, tears, saliva, and breast milk $[18,27,28]$. Despite of its designated location in the extracellular milieu, we found that not the secreted species, but rather the cell-associated $90 \mathrm{~K}$ exerted the reduction of particle infectivity. However, that does not exclude that secreted 90K displays antiviral functions in vivo that may depend on its reported immunostimulatory functions [11]. In line with this possibility, lack of mother-to-child transmission of HIV-1 correlated with elevated serum levels of $90 \mathrm{~K}$ in HIV-1 infected mothers [42]. Also, elevated levels of $90 \mathrm{~K}$ in breast milk were reported to induce protective effects against acute respiratory infections in breast milk fed children $[27,43]$. Furthermore, $90 \mathrm{~K}$ was recently described as a ligand of DC-SIGN and may interfere with the capturing of virions that may be required for the trans-infection of T-cells [44] at sites of primary infection.

A third criterion of many restriction factors is the existance of virally encoded antagonists against them, expressed either by HIV-1 or HIV-1 precursors. Work of our laboratory has provided preliminary evidence for the presence of an HIV-1 encoded antagonist of human 90K (unpublished observation), yet the specificity of the observed antagonism is not established and requires substantial experimental proof. Of note, low density of glycoprotein molecules on the virus surface is a specific property of HIV-1, which has been suggested to provide a selective advantage. Specifically, it has been hypothesized that this feature may enable efficient escape from antibody-mediated immune response [45]. It is unclear whether the reduction of infectivity, induced by $90 \mathrm{~K}$ mediated paucity of Env in virions, is outweighed by the advantage of better immune system escape. Future studies are required to determine the net antiviral effect of $90 \mathrm{~K}$ in vivo, as well as possible viral evasion strategies that may circumvent $90 \mathrm{~K}$-imposed antiviral activity.

\section{Conclusions}

This study establishes $90 \mathrm{~K}$ as an antiviral factor which impairs the infectivity of HIV-1 progeny, involving defective maturation and incorporation of Env glycoproteins. Further investigation and exploitation of its mode of action may provide a platform for the design of novel therapeutic antiviral approaches and widen our understanding of cell-mediated antiviral defense mechanisms.

\section{Methods}

\section{Cells}

293T cells, TZM-bl cells and the T-cell lines SupT1, JTag, PM1, CEM, Jurkat were cultured as recommended by ATCC. Cultures of primary PBMCs, from random human donors were generated as previously reported [46]. Taking of blood samples from humans and cell isolation were 
conducted with approval of the local ethics committee (Ethik-Komission der Universität Ulm, approval No. 298/ 12). Human blood samples were taken from healthy blood donors, who provided written informed consent for the collection of samples and subsequent cell isolation and analysis. Macrophages were differentiated for 10-15 days in the presence of $10 \%$ human $\mathrm{AB}$ serum (Sigma). $\mathrm{CD}^{+}$ T-cells were isolated from Buffy Coat by negative selection with the RosetteSep Human CD4 ${ }^{+} \mathrm{T}$ Cells Enrichment Cocktail (StemCell Technologies). For the 90K expression studies, $\mathrm{CD} 4^{+} \mathrm{T}$-cells were stimulated with IL-2/PHA for 2-3 days prior to IFN- $\alpha$ (Roche) or IFN- $\gamma$ (Sigma-Aldrich) treatment. 293T cells were transfected by calcium phosphate DNA precipitation, SupT1 cells were transfected by electroporation.

\section{Plasmids}

pcDNA6 and pcDNA6.90K-myc plasmids were provided by Ji Hee Lee, South Korea. pIRES2 90K-myc IRES GFP was generated by PCR amplification of 90K-myc and insertion into pIRES2-GFP (Clontech) using NheI and BamHI. The truncated variants of 90K-myc all contained the authentic signal peptide and were generated by amplification of $90 \mathrm{~K}$ with the following primers using HindIII and XbaI and insertion into pcDNA6: fwd GCAAGCTTGGATGACCCCTCCG and rev CGTCTAGAGGGGAGGAGGATGGCAAAGAGGCTTGC $(90 \mathrm{~K}(1,2)-$ myc); fwd CGAAGCTTATGACCCCTCCGAGGCTCTTCT GGGTGTGGCTGCTGGTTGCAGGAACCCAAGGCGTG AACGATGGTGACACCAGGAGCACCCACACCCTG GACCTC and rev CGTCTAGAAATCCGGGGCTTG TAGGTATCCT $(90 \mathrm{~K}(2,3)$-myc); fwd CGAAGCTTAT GACCCCTCCGAGGCTCTTCTGGGTGTGGCTGCTG GTTGCAGGAACCCAAGGCGTGAACGATGGTCTCC TCCCCCAGGACCCCTCGTTCCAGATG and rev CCT CTAGAGTCCACACCTGAGGAGTTGGTCAGG (90K (3,4)-myc). pcDNA6-mouse CypCAP-myc was generated by amplification of the mouse cDNA (Sino Biological Incorportion) using primers carrying HindIII and $\mathrm{XbaI}$ restriction sites (fwd GCAAGCTTATGGCTCTCCTG and rev GCTCTAGACACCATGTCAGTG) and ligation of the amplicon into pcDNA6/myc. Expression constructs for Glypican-3-HA and H7 Influenza virus HA (derived from A/chicken/Rostock/8/1934(H7N1)) were provided by Guido David and Wolfgang Garten, respectively. The expression plasmid pEbola GP was from Mark Goldsmith. The CD4 and the HIV-1 $1_{\mathrm{NL} 4.3}$ Env expression plasmid was from Oliver Keppler. The Vpu-IRES GFP expression construct and the respective control vector have been described elsewhere [47].

\section{Viruses}

Infectious HIV-1 was generated by calcium phosphate DNA precipitation of $293 \mathrm{~T}$ cells with plasmids encoding
HIV-1 and harvest of cell-free virion-containing supernatant. Plasmids encoding NL4.3, LAI, YU-2 were obtained from Oliver Keppler, plasmids encoding transmitter founder viruses ( $\mathrm{CHO} 58$, THRO, $\mathrm{CHO} 77)$ were obtained from Frank Kirchhoff. The construct pBR.HIV-1 NL4.3IRES GFP carries an IRES-EGFP cassette downstream of the nef ORF [48]. The expression plasmid for VSV-G was provided by Oliver Keppler. HIV-1 Ba-L was passaged on PM-1 cells.

\section{HIV-1 infectivity assay}

The infectivity of HIV-1 virions was assessed by applying a standardized TZM-bl based firefly luciferase assay or beta-galactosidase assay. Readouts were obtained luminometrically (RLU, relative light units). For calculation of the particle infectivity, luminometric counts were divided by the content of $\mathrm{p} 24$.

\section{Anti-p24 antigen ELISA}

Supernatants were analyzed for $\mathrm{p} 24$ content $(\mathrm{ng} / \mathrm{ml})$ by applying a home-made anti-p24 antigen ELISA [49].

\section{Cell viability assays}

Cells were stained with 7-AAD for detection of dead or unhealthy cells (BD PharMingen). For measuring metabolic activity, cell lysates were analyzed using the Cell Titer Glow assay (Promega). As a positive control for apoptosis induction or cell death, cells were treated UV-irradiated.

\section{SiRNAs and siRNA-mediated depletion of 90K expression}

The following siRNAs were used: control siRNA (Dharmacon), 90K-specific siRNA (GAAGCUCUGCCUACAGUUC, from MWG). TZM-bl cells and primary macrophages were transfected 2-3 times with siRNAs at the final concentration of 5-15 nM, using RNAiMax (Invitrogen). PBMCs were transfected twice by Amaxa nucleofection (Lonza) with final siRNA concentration of $2.5 \mu \mathrm{M}$. Knockdown efficiency was determined by quantitative RT-PCR of 90K mRNA and RNaseP mRNA and/or by anti-90K Western Blotting or anti-90K ELISA (eBioscience).

\section{K mRNA analysis}

Total RNA extraction from untreated or IFN-treated cells was performed with the Qiagen RNeasy kit (Qiagen), followed by DNase treatment (Ambion) and cDNA synthesis (NEB, Invitrogen). Quantification of relative 90K mRNA levels was performed with the Step One Plus Real Time PCR System (Applied Biosystems) using TaqMan PCR technology with the following oligonucleotide primers: 5'-GCTTCCTTCCTCTCTGCAATGA-3' (forward primer), 5'-TCAGGTGAGTAGGGCGACATC-3' (reverse primer), 5'-FAM-CTTCAACAACCGGCCAC-TAMRA-3' (fluorescent probe). Relative 90K mRNA levels were 
determined using the $\Delta \Delta \mathrm{Ct}$ method with human $R N a$ seP mRNA (Applied Biosystems) as internal reference. Each sample was analyzed in duplicates. Data analysis was performed using Applied Biosystems Step One Software v2.1.

\section{Confocal immunofluorescence microscopy}

Cells grown on coverslips were transfected with Lipofectamin2000 (Invitrogen) and fixed with $4 \%$ paraformaldehyde. They were permeabilized with $0.2 \%$ Saponin or $0.1 \%$ TritonX-100, blocked and stained with goat polyclonal anti-90K (R\&D Systems), followed by anti-goat Alexa647, goat polyclonal anti-myc (novus), followed by anti-goat Alexa488, or Chessie8 Hybridoma supernatant, followed by anti-mouse Alexa647. Coverslips were mounted with Mounting medium containing DAPI (Vectashield) and analysed with a Zeiss 710 LSM confocal microscope. Images were recorded and processed with the ZEN (2010) software. Quantification of 90K expression was performed by using the open-source KNIME (Kontanz Information Miner) platform (see http://tech.knime.org/faq\#q1_1) in combination with the KNIME Image Processing 1.0.3 extension. For segmentation, DAPI stained nuclei were used. The images were smoothed using a Gaussian Filter followed by a simple Otsu thresholding. Consecutively, cells were splitted using a standard cell clump splitter and additionally filtered by size. After identification of the cells, the intensity of each pixel was measured, the mean of intensity for each cell was calculated.

\section{Antibodies}

The following antibodies/antisera were used: goat polyclonal anti-90K (R\&D Systems), mouse anti-myc (provided by Jens von Einem), goat polycolonal anti-myc (Novus Biologicals), rabbit anti-MAPK (Santa Cruz), mouse anti-HIV-1 p24 (Exbio), rabbit anti-HIV-1 gp120 and mouse anti-HIV-1 gp41 (provided by Valerie Bosch), human 2G12 (NIH), mouse anti-HA (abcam), anti-Ebola GP (provided by Stephan Becker), anti H7-serum (provided by Wolfgang Garten), rabbit anti HIV-1 Vpu (provided by Ulrich Schubert), mouse anti-CD4 (abcam), anti-CD4-APC (BD).

\section{Immunoblotting}

Cells were lysed with M-PER Mammalian Protein Extraction Reagent (Pierce), and virions were prepared from supernatants and ultracentrifugation through a $20 \%(\mathrm{w} / \mathrm{v})$ sucrose cushion. Proteins were run on a $12.5 \%$ or $7.5 \%$ SDS-PAGE and transferred onto nitrocellulose. Blocked membranes were incubated with primary antibodies. Secondary antibodies conjugated to Alexa680/800 fluorescent dyes were used for detection by Odyssey Infrared Imaging System (LI-COR Biosciences) and quantification by Odyssey software.

\section{Coimmunoprecipitation}

Cells were lysed with $0.5 \%$ NP40 lysis buffer and a small aliquot was used for control of protein expression (Input). Residual lysate was filled up to final volume of $500 \mu \mathrm{l}$ with $0.5 \% \mathrm{NP} 40$ and incubated with antibody for 1 hour at $4{ }^{\circ} \mathrm{C}$. $30 \mu \mathrm{l}$ G-Sepharose Beads (GE-Healthcare) were added and precipitated 90 minutes at $4{ }^{\circ} \mathrm{C}$. Beads were washed with $0.1 \%$ NP40, treated with Western Blot Sample Buffer and boiled for 5 minutes. Supernatants contained the precipitated proteins.

\section{Digestion with PNGase or EndoH}

Cell lysates were treated with PNGase (NEB BioLabs) and EndoH (NEB BioLabs) according to instructor's protocol. Digestion was performed with 625 Units PNGase for $20 \mathrm{mi}-$ nutes or with 100 Units EndoH for 5 minutes at $37^{\circ} \mathrm{C}$.

\section{Additional files}

Additional file 1: Figure S1. Heterologous $90 \mathrm{~K}$ levels compared to endogenous 90K levels. (A) 293T cells were cotransfected with various amounts of pcDNA6.90K-myc $(1.3,0.4,0.15,0.05,0.02 \mu \mathrm{g})$, stimulated with 100 Units IFN-a, IFN- $\gamma$ for 48 h, or left untreated. (B) Western Blot of cell lysates of 293T cells overexpressing various amounts of 90K-myc (A) and untreated TZM-bl cells. (C) Western Blot of cell lysates of 293T cells overexpressing various amounts of $90 \mathrm{~K}-\mathrm{myc}(\mathrm{A})$ and primary macrophages stimulated with 100 IFN- $a$, IFN- $\gamma$ for 48 h, or left untreated. The numbers depict the relative $90 \mathrm{~K}$ expression, measured by normalization of the $90 \mathrm{~K}$ signal to the MAPK signal obtained by Infrared-imaging based quantification. The ratio obtained for the lowest antivirally active 90K plasmid dose $(0.15 \mu \mathrm{g}, A)$, the ratio obtained for TZM-bl cell lysates (B) or the ratio obtained for untreated macrophages $(C)$ was set to 1 , respectively.

Additional file 2: Figure S2. 90K reduces the particle infectivity of multiple HIV-1 strains. (A) 293T cells were cotransfected with the indicated proviral plasmids and highest amount of pcDNA6.90K-myc or empty vector. Supernatants were analyzed for infectious HIV-1 using a luminometric TZM-based luciferase assay. Shown are the results of one representative experiment out of three-six. (B) Relative levels of particle infectivity, defined as HIV-1 infectivity per ng p24 capsid are depicted. (C) Sucrose cushionpurified virions were analyzed by immunoblotting. Percentages indicate the relative gp120 incorporation, as measured by Infrared imaging-based quantification of the amount of gp120 per p24. The signal intensity in absence of $90 \mathrm{~K}$ expression was set to $100 \%$. (D) Cell lysates were analyzed by immunoblotting using the indicated antibodies. Numbers indicate the efficiency of gp160 processing. * : $p<0.05 ;{ }^{* *}: p<0.02$ (Student's T-Test).

Additional file 3: Figure S3. 90K-myc expression is not associated with toxicity or reduced metabolic activity. (A) 293T cells were transfected with pcDNA6.90K-myc $(1.3 \mu \mathrm{g})$, empty vector, or UV-irradiated and stained two days post transfection and one day post UV-irradiation with 7-AAD. Shown are representative dot plots of one experiment out of two. Numbers indicate percentage of 7-AAD-positive cells. (B) Quantification of 7-AAD FACS analysis. (C) Cells were lysed and analysed for metabolic activity by Cell Titer Glow assay. Shown are the RLU of triplicates obtained from one representative experiment out of two.

Additional file 4: Figure S4. $90 \mathrm{~K}$ does not reduce the cell surface levels of CD4. (A) 293T cells were cotransfected with pcDNA.CD4 and pIRES2EGFP.90K-myc or empty vector, Cells were stained with APCconjugated anti-CD4 and analyzed by flow cytometry. Shown are representative dot plots of one experiment out of three. (B) 293T cells were cotransfected with pcDNA.CD4 and pVpu-IRES GFP or empty vector and processed like in (A). (C) CD4 cell surface levels were calculated by comparing, within the same sample, CD4 levels on non-GFP-expressing cells (gate P2) with CD4 levels on cells with medium-high GFP expression 
levels (gate P3). CD4 levels on vector transfected cells were set to 100\%. (D) An aliquot of the cells shown in (A) and (B) were lyzed and analyzed by Western Blotting using the indicated antibodies.

Additional file 5: Figure S5. 90K and Env colocalize to a high extent. (A) $293 \mathrm{~T}$ cells were cotransfected with pcDNA6.90K-myc and an HIV-1 Env expression plasmid, and stained for 90K-myc (green) and Env (red). Scale bar: $10 \mu \mathrm{m}$. (B) The classic colocalization coefficient was calculated for the colocalization of $90 \mathrm{~K}$ protein with Env protein or vice versa using ZEN2010 software. The data represent the arithmetic mean \pm S.D. of 105 analyzed cells.

Additional file 6: Figure S6. No evidence for a direct interaction of $90 \mathrm{~K}$ and HIV-1 Env. (A-C) 293T cells were cotransfected with pcDNA6, pcDNA6.90K-myc, an HIV-1 Env expression plasmid, pCDNA.CD4 or a combination out of these. (A) 90K, CD4 and bound proteins were precipitated from cell lysates by an anti-90K or anti-CD4 antibody, respectively. (B) 90K, CD4 and bound proteins were precipitated from cell lysates by an anti-myc or anti-CD4 antibody, respectively. (C) Env and bound proteins were precipitated from cell lysates by an anti-gp120 antibody. For each experimental set up, an aliquot of whole cell lysate for expression control (Input) and the precipitated proteins were analyzed by Immunoblot with indicated antibodies.

Additional file 7: Figure S7. 90K does not retain Env in the ER. (A-B) 293T cells were cotransfected with pBR.HIV-1 IRES GFP and vector or pcDNA6.90K-myc. (A) Cell lysates were treated with PNGase. (B) Cell lysates were treated with EndoH. Deglycosylated and control proteins were analyzed by Western Blot. Numbers indicate the efficiency of gp41 processing, calculated as the signal ratio of gp41 relative to $(g p 41+g p 160)$, or the percentage of deglycosylated gp160 to the total gp160 signal.

Additional file 8: Figure S8. Species specificity of 90K-imposed antiviral activity. (A) 293T cells were cotransfected with pBR.HIV-1 NL4.3-IRES GFP and $1.3 \mu \mathrm{g}$ of the indicated expression constructs or empty vector. Two days post transfection, supernatants were analyzed for particle infectivity, defined as infectivity per ng p24. Cell lysates were analyzed by immunoblotting. (B) Sucrose cushion-purified virions were analyzed by immunoblotting. Shown is the relative gp120 incorporation, as measured by Infrared imaging-based quantification of the amount of gp120 per p24. The signal intensity in absence of 90K expression was set to $100 \%$. (C) Cell lysates were analyzed by immunoblotting. Shown is the percentage of gp120, as measured by Infrared imaging-based quantification of the amount of gp120 per (gp120+ gp160). Bar diagrams show the arithmetic means \pm S.E.M. of 3-4 independent experiments. The Western Blot shown is representative for one of the experiments included in the calculation. ${ }^{*}: \mathrm{p}<0.02 ;$ n.s. : $>0.05$ (Student's T-Test).

\section{Abbreviations}

A.U: Arbitrary units; HIV: Human immunodeficiency virus; IFN: Interferon; LGALS3BP: Lectin galactoside-binding soluble 3 binding protein; MFI: Mean fluorescence intensity; RLU: Relative light units.

\section{Competing interests}

The authors declare that they have no competing interests.

\section{Authors' contributions}

VL and CG conceptualized and designed the study; VL, KS, NS, CK, CMS, TW, DK, CG performed the study; TW and CD performed the

immunofluorescence-based quantification of 90K expression; VL, KS, CK, CMS, CG analyzed data; VL and CG wrote the paper. JM and FK provided reagents. All the authors reviewed the manuscript and approved the final version.

\section{Acknowledgments}

We thank Sebastian Bolduan, Valerie Bosch, Guido David, Giada Frascaroli, Wolfgang Garten, Mark Goldsmith, Beatrice Hahn, Stefano lacobelli, Oliver Keppler, Ji Hee Lee, Xuehua Li, Barbara Müller, Ulrich Schubert, and Jens von Einem for the kind gift of reagents. We are grateful to Daniel Sauter and David Palesch for helpful comments on the manuscript. This work was supported by the Leibniz Award of the German Research Council (DFG) to Frank Kirchhoff, a PhD Fellowship of Baden-Württemberg (LGFG Stipend) to $\mathrm{VL}$, by a Margarete von Wrangell Habilitation Fellowship to CG and by a DFG Research Grant (GO2153/2-1) to CG.

\section{Author details}

${ }^{1}$ Institute of Molecular Virology, Ulm University Medical Center, Ulm, Germany. ${ }^{2}$ Nycomed Chair of Bioinformatics and Information Mining, University of Konstanz, Konstanz, Germany. ${ }^{3}$ Doerenkamp-Zbinden Department of in vitro Toxicology and Biomedicine, University of Konstanz, Konstanz, Germany. ${ }^{4}$ TWINCORE, Institute of Experimental Virology, Feodor-Lynen-Strasse 7, 30625 Hannover, Germany.

Received: 16 April 2013 Accepted: 14 October 2013

Published: 24 October 2013

\section{References}

1. Sheehy AM, Gaddis NC, Choi JD, Malim MH: Isolation of a human gene that inhibits HIV-1 infection and is suppressed by the viral Vif protein. Nature 2002, 418(6898):646-650.

2. Neil SJ, Zang T, Bieniasz PD: Tetherin inhibits retrovirus release and is antagonized by HIV-1 Vpu. Nature 2008, 451(7177):425-430.

3. Van Damme N, Goff D, Katsura C, Jorgenson RL, Mitchell R, Johnson MC, Stephens EB, Guatelli J: The interferon-induced protein BST-2 restricts HIV-1 release and is downregulated from the cell surface by the viral Vpu protein. Cell Host Microbe 2008, 3(4):245-252.

4. Hrecka K, Hao C, Gierszewska M, Swanson SK, Kesik-Brodacka M, Srivastava S, Florens L, Washburn MP, Skowronski J: Vpx relieves inhibition of HIV-1 infection of macrophages mediated by the SAMHD1 protein. Nature 2011, 474(7353):658-661.

5. Laguette N, Bregnard C, Benichou S, Basmaciogullari S: Human immunodeficiency virus (HIV) type-1, HIV-2 and simian immunodeficiency virus Nef proteins. Mol Aspects Med 2010, 31(5):418-433.

6. Baldauf HM, Pan X, Erikson E, Schmidt S, Daddacha W, Burggraf M, Schenkova K, Ambiel I, Wabnitz G, Gramberg T, et al: SAMHD1 restricts HIV1 infection in resting CD4(+) T cells. Nat Med 2012, 18(11):1682-1687.

7. Malim MH, Bieniasz PD: HIV restriction factors and mechanisms of evasion. Cold Spring Harb Perspect Med 2012, 2(5):a006940.

8. Audige A, Urosevic M, Schlaepfer E, Walker R, Powell D, Hallenberger S, Joller H, Simon HU, Dummer R, Speck RF: Anti-HIV state but not apoptosis depends on IFN signature in CD4+ T cells. J Immunol 2006, 177(9):6227-6237.

9. Rotger M, Dang KK, Fellay J, Heinzen EL, Feng S, Descombes P, Shianna KV Ge D, Gunthard HF, Goldstein DB, et al: Genome-wide mRNA expression correlates of viral control in CD4+ T-cells from HIV-1-infected individuals. PLoS Pathog 2010, 6(2):e1000781.

10. Brakebusch C, Sures I, Jallal B, Mossie K, Fusco O, lacobelli S, Ullrich A: Isolation and functional characterization of the human $90 \mathrm{~K}$ promoter. Genomics 1999, 57(2):268-278.

11. Ullrich A, Sures I, D'Egidio M, Jallal B, Powell TJ, Herbst R, Dreps A, Azam M, Rubinstein M, Natoli C, et al: The secreted tumor-associated antigen $90 \mathrm{~K}$ is a potent immune stimulator. J Biol Chem 1994 269(28):18401-18407.

12. Marcello T, Grakoui A, Barba-Spaeth G, Machlin ES, Kotenko SV, MacDonald MR, Rice CM: Interferons alpha and lambda inhibit hepatitis $C$ virus replication with distinct signal transduction and gene regulation kinetics. Gastroenterology 2006, 131(6):1887-1898.

13. Waddell SJ, Popper SJ, Rubins KH, Griffiths MJ, Brown PO, Levin M, Relman DA: Dissecting interferon-induced transcriptional programs in human peripheral blood cells. PLoS One 2010, 5(3):e9753.

14. lacobelli S, Scambia G, Natoli C, Panici PB, Baiocchi G, Perrone L, Mancuso S: Recombinant human leukocyte interferon-alpha $2 \mathrm{~b}$ stimulates the synthesis and release of a $90 \mathrm{~K}$ tumor-associated antigen in human breast cancer cells. Int J Cancer 1988, 42(2):182-184.

15. Marth C, Dreps A, Natoli C, Zeimet AG, Lang T, Widschwendter M, Daxenbichler G, Ullrich A, lacobelli S: Effects of type-I and -II interferons on 90K antigen expression in ovarian carcinoma cells. Int J Cancer 1994, 59(6):808-813.

16. Natoli C, Garufi C, Tinari N, D'Egidio M, Lesti G, Gaspari LA, Visini R, lacobelli S: Dynamic test with recombinant interferon-alpha-2b: effect on $90 \mathrm{~K}$ and other tumour-associated antigens in cancer patients without evidence of disease. Br J Cancer 1993, 67(3):564-567.

17. Briggs NC, Natoli C, Tinari N, D'Egidio M, Goedert JJ, lacobelli S: A 90-kDa protein serum marker for the prediction of progression to AIDS in a cohort of HIV-1+ homosexual men. AIDS Res Hum Retroviruses 1993, 9(9):811-816. 
18. Groschel B, Braner JJ, Funk M, Linde R, Doerr HW, Cinatl J Jr, lacobelli S: Elevated plasma levels of 90K (Mac-2 BP) immunostimulatory glycoprotein in HIV-1-infected children. J Clin Immunol 2000, 20(2):117-122.

19. lacobelli S, Natoli C, D'Egidio M, Tamburrini E, Antinori A, Ortona L: Lipoprotein 90K in human immunodeficiency virus-infected patients: a further serologic marker of progression. J Infect Dis 1991, 164(4):819.

20. Longo G, Natoli C, Rafanelli D, Tinari N, Morfini M, Rossi-Ferrini P, D'Ostilio N, lacobelli S: Prognostic value of a novel circulating serum 90K antigen in HIV-infected haemophilia patients. Br J Haematol 1993, 85(1):207-209.

21. Natoli C, Dianzani F, Mazzotta F, Balocchini E, Pierotti P, Antonelli G, lacobelli S: $90 \mathrm{~K}$ protein: a new predictor marker of disease progression in human immunodeficiency virus infection. J Acquir Immune Defic Syndr 1993, 6(4):370-375.

22. Natoli C, lacobelli S, Ghinelli F: Unusually high level of a tumor-associated antigen in the serum of human immunodeficiency virus-seropositive individuals. J Infect Dis 1991, 164(3):616-617.

23. lacobelli S, Arno E, D'Orazio A, Coletti G: Detection of antigens recognized by a novel monoclonal antibody in tissue and serum from patients with breast cancer. Cancer Res 1986, 46(6):3005-3010.

24. Linsley PS, Horn D, Marquardt H, Brown JP, Hellstrom I, Hellstrom KE, Ochs $\mathrm{V}$, Tolentino E: Identification of a novel serum protein secreted by lung carcinoma cells. Biochemistry 1986, 25(10):2978-2986.

25. Resnick D, Pearson A, Krieger M: The SRCR superfamily: a family reminiscent of the Ig superfamily. Trends Biochem Sci 1994, 19(1):5-8.

26. Laferte S, Loh LC, Keeler V: Monoclonal antibodies specific for human tumor-associated antigen $90 \mathrm{~K} / \mathrm{Mac}-2$ binding protein: tools to examine protein conformation and function. J Cell Biochem 2000, 77(4):540-559.

27. D'Ostilio N, Sabatino G, Natoli C, Ullrich A, lacobelli S: 90K (Mac-2 BP) in human milk. Clin Exp Immunol 1996, 104(3):543-546.

28. Koths K, Taylor E, Halenbeck R, Casipit C, Wang A: Cloning and characterization of a human Mac-2-binding protein, a new member of the superfamily defined by the macrophage scavenger receptor cysteine-rich domain. J Biol Chem 1993, 268(19):14245-14249.

29. Inohara H, Akahani S, Koths K, Raz A: Interactions between galectin-3 and Mac-2binding protein mediate cell-cell adhesion. Cancer Res 1996, 56(19):4530-4534.

30. Checkley MA, Luttge BG, Freed EO: HIV-1 envelope glycoprotein biosynthesis, trafficking, and incorporation. J Mol Biol 2011, 410(4):582-608

31. Crooks ET, Tong T, Osawa K, Binley JM: Enzyme digests eliminate nonfunctional Env from HIV-1 particle surfaces, leaving native Env trimers intact and viral infectivity unaffected. J Virol 2011, 85(12):5825-5839.

32. Nachmias D, Sklan EH, Ehrlich M, Bacharach E: Human immunodeficiency virus type 1 envelope proteins traffic toward virion assembly sites via a TBC1D20/Rab1-regulated pathway. Retrovirology 2012, 9:7.

33. Hellstern S, Sasaki T, Fauser C, Lustig A, Timpl R, Engel J: Functional studies on recombinant domains of Mac-2-binding protein. J Biol Chem 2002, 277(18):15690-15696.

34. Trahey M, Weissman IL: Cyclophilin C-associated protein: a normal secreted glycoprotein that down-modulates endotoxin and proinflammatory responses in vivo. Proc Natl Acad Sci USA 1999, 96(6):3006-3011.

35. Muller SA, Sasaki T, Bork P, Wolpensinger B, Schulthess T, Timpl R, Engel A, Engel J: Domain organization of Mac-2 binding protein and its oligomerization to linear and ring-like structures. J Mol Biol 1999, 291(4):801-813.

36. Bieniasz PD, Cullen BR: Multiple blocks to human immunodeficiency virus type 1 replication in rodent cells. J Virol 2000, 74(21):9868-9877.

37. Goujon C, Malim MH: Characterization of the alpha interferon-induced postentry block to HIV-1 infection in primary human macrophages and T cells. J Virol 2010, 84(18):9254-9266.

38. Hansen BD, Nara PL, Maheshwari RK, Sidhu GS, Bernbaum JG, Hoekzema D, Meltzer MS, Gendelman HE: Loss of infectivity by progeny virus from alpha interferon-treated human immunodeficiency virus type 1-infected T cells is associated with defective assembly of envelope gp120. J Virol 1992, 66(12):7543-7548.

39. Dianzani F, Castilletti C, Gentile M, Gelderblom HR, Frezza F, Capobianchi MR: Effects of IFN alpha on late stages of HIV-1 replication cycle. Biochimie 1998, 80(8-9):745-754.

40. Binley JM, Sanders RW, Master A, Cayanan CS, Wiley CL, Schiffner L, Travis B, Kuhmann S, Burton DR, Hu SL, et al: Enhancing the proteolytic maturation of human immunodeficiency virus type 1 envelope glycoproteins. J Virol 2002, 76(6):2606-2616.

41. Wang P, Heitman J: The cyclophilins. Genome Biol 2005, 6(7):226.
42. Pelliccia P, Galli L, de Martino M, Chiarelli F, Verrotti A, Sabatino G, Fornarini B, lacobelli S, Natoli C: Lack of mother-to-child HIV-1 transmission is associated with elevated serum levels of $90 \mathrm{~K}$ immune modulatory protein. Aids 2000, 14(4):F41-F45.

43. Fornarini B, lacobelli S, Tinari N, Natoli C, De Martino M, Sabatino G: Human milk 90K (Mac-2 BP): possible protective effects against acute respiratory infections. Clin Exp Immunol 1999, 115(1):91-94.

44. Nonaka M, Ma BY, Imaeda H, Kawabe K, Kawasaki N, Hodohara K, Andoh A Fujiyama Y, Kawasaki T: Dendritic cell-specific intercellular adhesion molecule 3-grabbing non-integrin (DC-SIGN) recognizes a novel ligand, Mac-2-binding protein, characteristically expressed on human colorectal carcinomas. J Biol Chem 2011, 286(25):22403-22413.

45. Klein JS, Bjorkman PJ: Few and far between: how HIV may be evading antibody avidity. PLoS Pathog 2010, 6(5):e1000908

46. Goffinet C, Allespach I, Oberbremer L, Golden PL, Foster SA, Johns BA Weatherhead JG, Novick SJ, Chiswell KE, Garvey EP, et al: Pharmacovirological impact of an integrase inhibitor on human immunodeficiency virus type 1 CDNA species in vivo. J Virol 2009, 83(15):7706-7717.

47. Schindler M, Rajan D, Banning C, Wimmer P, Koppensteiner H, Iwanski A Specht A, Sauter D, Dobner T, Kirchhoff F: Vpu serine 52 dependent counteraction of tetherin is required for HIV-1 replication in macrophages, but not in ex vivo human lymphoid tissue. Retrovirology 2010, 7:1.

48. Wildum S, Schindler M, Munch J, Kirchhoff F: Contribution of Vpu, Env, and Nef to CD4 down-modulation and resistance of human immunodeficiency virus type 1-infected T cells to superinfection. J Virol 2006, 80(16):8047-8059.

49. Habermann A, Krijnse-Locker J, Oberwinkler H, Eckhardt M, Homann S, Andrew A, Strebel K, Krausslich HG: CD317/tetherin is enriched in the HIV1 envelope and downregulated from the plasma membrane upon virus infection. J Virol 2010, 84(9):4646-4658.

doi:10.1186/1742-4690-10-111

Cite this article as: Lodermeyer et al: $90 \mathrm{~K}$, an interferon-stimulated gene product, reduces the infectivity of HIV-1. Retrovirology 2013 10:111.

\section{Submit your next manuscript to BioMed Central and take full advantage of:}

- Convenient online submission

- Thorough peer review

- No space constraints or color figure charges

- Immediate publication on acceptance

- Inclusion in PubMed, CAS, Scopus and Google Scholar

- Research which is freely available for redistribution 